Pacific Journal of Mathematics

FIRST AND SECOND CATEGORY ABELIAN GROUPS WITH
THE $n$-ADIT TOPOLOGY 


\title{
FIRST AND SECOND CATEGORY ABELIAN GROUPS WITH THE n-ADIC TOPOLOGY
}

\author{
EDGAR J. HowARD
}

Throughout this paper the word group shall mean Abelian group. The $n$-adic topology of a group $G$ is formed by taking the subgroups $k ! G$ as a base for the neighborhood system of the identity where $k$ is a nonnegative integer. In this paper we list some properties of first and second category groups with the $n$-adic topology (a group is of first category if it is a countable union of nowhere dense sets).

We characterize first and second category groups and prove the following:

Theorem: A torsion group is of second category if and only if $G=H \oplus D$ where $H$ is bounded and $D$ is divisible.

Theorem: Every torsion homomorphic image of a second category (e.g. complete) group is the direct sum of a bounded group and a divisible group.

Theorem: If $G$ is reduced and of second category and $G=\sum G_{\alpha}$, then there exists an integer $n$ such that $n G_{\alpha}=0$ for all but finitely many $\alpha$.

Theorem: If $T$ is torsion, $T$ is isomorphic to the torsion subgroup of a second category group.

The notation and terminology will be essentially that of L. Fuchs in [1]. The topological notations will be those of [6]. We note the following.

1. If $A$ is a subset (subgroup) of $B$ we write $A \leqq B(A \leqq B)$.

2. $\langle x\rangle$ denotes the cyclic group generated by $x$.

3. + means sum not necessarily direct, and $\oplus$ means direct sum.

4. By a first (second) category group $G$ we shall mean that $G$ is of first (second) category with the $n$-adic topology.

5. The term "closed" will be used in the topological sense.

2. On first and second category groups. In this section we shall use the facts that homomorphisms are continuous maps in the $n$-adic topology, and "onto" homomorphisms are open maps in this topology. The proof of the following is routine.

LEMMA 2.1. If $f$ is a homomorphism from $G$ onto $H$, then

Received September 22, 1964, This work was partially supported by the National Science Foundation under Research Grant GP 377. 
(i) $f^{-1}$ maps first category sets into first category sets and

(ii) if $A$ is of second category in $G$, then $f(A)=H$ is of second category.

THEOREM 2.2. Let $G$ be an Abelian group with its n-adic topology. Then $G$ is of first category if and only if $G$ can be mapped homomorphically onto a group of first category in its n-adic topology.

Proof. If $G$ is of first category it can be mapped by the identity mapping onto itself. Conversely, if $G$ can be mapped homomorphically onto a first category group, say $H, f^{-1}(H)=G$ is of first category by Lemma C.1.

REMARK. Since a group is of second category if and only if it is not of first category, Theorem 2.2 also characterizes second category groups.

We will now show that all unbounded reduced torsion groups are of first category. We note that bounded groups are of second category since they are discrete in the $n$-adic topolopy, and divisible groups are of second category since they are indiscrete in the $n$-adic topology.

Lemma 2.3. If $G$ is an unbounded torsion group with $\cap k ! G=$ 0 ; then $G$ is of first category.

Proof. Let $G[n]=\{x: n x=0\}$, then we have $G=\cup_{n} G[n]$ and $G[n]$ is nowhere dense.

Lemma 2.1 yields:

Proposition 2.4. If $G$ is of second category and $K$ is any subgroup of $G$, then $G / K$ is of second category.

The following corollaries are easily proved.

CoRollary 2.5. If $G$ is of second category and $H$ is a direct summand of $G$, then $H$ is of second category.

CoRollary 2.6. If $G=H \oplus K$ and $H$ is of first category in itself, then $G$ is of first category.

If $G^{1}=\cap k ! G$, by the next theorem we see that to classify $G$ as a second category group we only need to consider $G / G^{1}$. 
THEOREM 2.7. A group $G$ is of second category if and only if $G / G^{1}$ is of second category.

Proof. If $G$ is of second category, then Proposition 2.4 implies that $G / G^{1}=\bar{G}$ is of second category. It is routine to show that the natural homomorphism from $G$ to $G / G^{1}$ is a closed mapping. To prove that $G$ is of second category it then suffices to show that if $F$ is a closed subset of $G$ and if $\bar{F}$ is the image of $F$ in $G / G^{1}$, then the interior of $\bar{F}$ nonempty implies the interior of $F$ is nonempty. To prove the latter, suppose $F$ and $\bar{F}$ are as above and the interior of $\bar{F}$ is nonempty, then there exists an integer $k$ such that $\bar{x}+k ! \bar{G} \subseteq \bar{F}$. From this we obtain that $x+k ! G \leqq F+G$ where $x+G^{1}=\bar{x}$. Since $F$ is closed, $F+G^{1} \subseteq F$. Hence $x+k ! G \subseteq F$ and thus the interior of $F$ is nonempty.

Corollary 2.8. If $H$ is of second category and $D$ is divisible, then $H \oplus D$ is of second category.

$$
\begin{array}{r}
\text { Proof. Let } G=H \oplus D \text {, then } G^{1}=H^{1} \oplus D \text { and } \\
G / G^{1}=(H \oplus D) /\left(H^{1} \oplus D\right) \cong H / H^{1} .
\end{array}
$$

THEOREM 2.9. A torsion group $G$ is of second category if and only if $G=H \oplus D$ where $H$ is bounded and $D$ is divisible.

Proof. If $G$ is of second category, then $G / G^{1}$ is of second category and by Lemma 2.3, $G / G^{1}$ is bounded and hence $G^{1}$ is divisible. For the converse use Corollary 2.8 .

Theorem 2.9 yields the following:

THEOREM 2.10. A torsion group is of first category if and only if its reduced part is unbounded.

We now list some corollaries of the preceding results.

CoROLLARY 2.11. Every torsion homomorphic image of a second category group is the direct sum of a divisible group and a bounded group.

Proof. Lemma 2.1 and Theorem 2.9.

Remark. In Problem 12 of [1], Fuchs asks: When has a torsion free group an unbounded torsion complete $p$-group as a homomorphic 
image? Lemmas 2.1 and 2.3 yield that torsion free second category groups do not have this property.

Corollary 2.11. with the Baire Category theorem gives:

COROLLARY 2.12. Every torsion homomorphic image of a complete group is the direct sum of a divisible group and a bounded group.

CoRollary. 2.13. If $G$ is of second category, then $G$ splits if and only if the maximal torsion subgroup of $G$ is the direct sum of a divisible group and a bounded group.

At this point we mention some further results. It can be easily shown that if $G$ is a countable unbounded group with $\cap k ! G=0$, then $G$ is of first category. In particular, the infinite cyclic group is of first category. Since every free group can be mapped onto the infinite cyclic group, we have that all free groups are of first category.

\section{A structure theorem for second category groups.}

THeOREM 3.1. Suppose $G$ is reduced and is of second category in its n-adic topology. If $G=\Sigma G_{\alpha}$, then there exists an integer $n$ such that $n G_{\alpha}=0$ for all but finitely many $\alpha$.

Proof. Let $B=\left\{\alpha: G_{\alpha} \text { is a torsion group }\right\}_{\text {. Then }} \sum_{\alpha \in_{B}} G_{\alpha}$ is a direct summand of $G$, hence a reduced torsion group of second category, hence it is bounded. If the complement of $B$ is finite the theorem is proved. Otherwise let $\alpha(1), \alpha(2), \cdots$ be an infinite sequence of indices not in $B$. Since each $G_{\alpha}$ is reduced there is, for each $n$, an integer $k_{n}>1$ such that $k_{n} G_{\alpha(n)} \neq G_{\alpha(n)}$. Let $b_{n}=k_{1} \cdots k_{n}$. Then $0 \neq b_{n} G_{\alpha(n)} \neq G_{\alpha(n)}$ and $\Sigma G_{\alpha(n)} / b_{n} G_{\alpha(n)}$ is a reduced torsion homomorphic image of $G$ having unbounded order.

4. Some existence theorems for second category groups. Up to this point the only examples of groups of second category (with no elements of infinite height) with which we have dealt have been complete groups. In this section we prove some theorems which give the existence of non-complete mixed and torsion free second category groups with no elements of infinite height.

The following is a special case of some results of Pettis in [7]. We will use the fact that a subgroup $H$ of $G$ is dense in $G$ if and only if $G / H$ is divisible.

THEOREM 4.1. (Pettis [7]) Let $G$ be a second category group in its n-adic topology and let $H$ be a proper subgroup of $G$. If 
$M \in\{K: H \leqq K \leqq G$ and $K \cap P=\phi\}$ and $M$ is maximal with respect to $M \cap P=\phi$ where $P \subseteq G \backslash H$ and $P$ is countable, then $M$ is of second category in $G$.

The next lemma is a slight modification of Lemma 2 of [3]. The proof is essentially the same.

LEMma 4.2. If $H$ is a proper pure dense subgroup of a group $G$ and $H \leqq M$ with $M$ maximal with respect to $M \cap P=\phi$ where $P=\langle x\rangle \backslash\{0\} \subseteq G \backslash H$ for $x \notin H$, then $M$ is pure in $G$.

THEOREM 4.3. If $G$ is of second category and $H$ is a proper pure dense subgroup of $G$, then there exists a proper pure subgroup $M$ of $G$ which is of second category in $G$ such that $H \leqq M$.

Proof. By Lemma 2 of [5] there exist $x \notin H$ such that $\langle x\rangle \cap H=0$. Let $P=\langle x\rangle \mid\{0\}$. Then $P \subseteq G \mid H$ and is countable. By Theorem 5.1 there exists a second category group $M$ such that $M \cap P=\phi$ with $H \leqq M<G$. Now, with Lemma 4.2, we have that $M$ is pure.

Proposition 4.4. If $G$ is of second category in its $n$-adic topology and $H$ is a pure subgroup of second category in $G$, then $H$ is of second category in the $n$-adic topology of $H$.

Proof. Clearly, $H$ is of second category in its relative topology. Since $H$ is pure in $G$, the relative topology and the $n$-adic topology are the same. Thus $H$ is of second category in itself.

Proposition 4.5. There exists noncomplete mixed groups which are of second category in their $n$-adic topology.

Proof. Let $H$ be an unbounded torsion $p$-group with $\cap k ! H=0$. Let $G$ be the completion of $H$, then $H$ is a pure proper dense subgroup of $G$. By Theorem 4.3 there exists a pure proper second category subgroup $M$ of $G$ containing $H$. By Proposition 4.4 $M$ is of second category in its own $n$-adic topology. Since $M$ contains $H$ and is properly contained in the completion of $H, M$ is not complete.

For the next proposition we will use the fact that the $p$-adic integers, $P$, are complete in the $p$-adic topology to give an example of a torsion free second cotegory group which is not complete. Recall that if $x \in P, x$ can be represented uniquely as $x=x_{0}+x_{1} p+x_{2} p^{2}+\cdots$ where $0 \leqq x_{n} \leqq p-1$. Let $H$ be the subgroup of $P$ consisting of the elements $h=x_{0}+x_{1} p+\cdots+x_{n} p^{n}$ with $x_{k}=0$ for all $k$ greater than 
some $n(h)$. By the uniqueness of representation of the elements in $P$ we have that $H$ is pure in $P$. It is easily shown that $P / H$ is divisible. We now have that $H$ is a pure proper dense subgroup of a torsion free complete group. From Theorem 4.3 we know that there exists a proper pure subgroup $M$ of $P$ which is of second category such that $H<M$. By Proposition $4.4 M$ is of second category in its $p$-adic topology. We have thus proved the following.

Proposition 4.6. There exist noncomplete second category groups in their $n$-adic topology which are torsion free.

5. Embedding torsion groups in second category groups. In this section we consider the following question: If $T$ is any torsion group, does there exist a second category group with the $n$-adic topology such that $T$ is the maximal torsion subgroup of this group? The answer is in the affirmative.

If $T$ is divisible, $T$ is of second category. For the reduced case we use the following proved by Harrison in [2]. If $A$ is torsion, then $\operatorname{Hom}(A, B)$ is complete for all groups $B$. Since $\operatorname{Hom}(A, B)$ is complete it is of second category.

Proposition 5.1. If $G$ is either torsion or torsion free, then $\operatorname{Ext}(G, X)$ is of second category for all groups $X$.

Proof. If $G$ is torsion free, then $\operatorname{Ext}(G, X)$ is divisible and is of second category. Suppose $G$ is torsion and let $X$ be any group. Let $D$ be a divisible group containing $X$. This yields the following exact sequences:

$$
0 \rightarrow X \rightarrow D \rightarrow D / X \rightarrow 0
$$

and

$$
\begin{aligned}
0 \rightarrow \operatorname{Hom}(G, X) & \rightarrow \operatorname{Hom}(G, D) \rightarrow \operatorname{Hom}(G, D / X) \\
& \rightarrow \operatorname{Ext}(G, X) \rightarrow \operatorname{Ext}(G, D)=0 .
\end{aligned}
$$

Thus, $\operatorname{Hom}(G, D / X) \rightarrow \operatorname{Ext}(G, X) \rightarrow 0$ is exact and $\operatorname{Hom}(G, D / X)$ is of second category. Hence by Lemma 2.1 $\operatorname{Ext}(G, X)$ is of second category.

THEOREM 5.2. If $T$ is a reduced torsion group, then $T$ is isomorphic to the maximal torsion subgroup of a second category group.

Proof. In [2] Harrison shows that for a reduced torsion group $T$ the following is exact: 


$$
0 \rightarrow T \rightarrow \operatorname{Ext}(Q / Z, T) \rightarrow \operatorname{Ext}(Q, T) \rightarrow 0 .
$$

This implies that $\operatorname{Ext}(Q / Z, T) / T \cong \operatorname{Ext}(Q, T)$. Again by [2], $\operatorname{Ext}(Q, T)$ is torsion free divisible. Thus $T$ is isomorphic to the torsion subgroup of $\operatorname{Ext}(Q / Z, T)$. By Proposition 5.1 Ext $(Q / Z, T)$ is of second category. Thus for any reduced torsion group $T, T$ is the maximal torsion subgroup of the second category group $\operatorname{Ext}(Q / Z, T)$.

Remark. Corollaries to Theorem 6.3 are solutions to Problems 32(a) and 33(a) of [1]. Problem 32(a) was solved by E. A. Walker and A. L. S. Corner (independently) and Problem 33(a) was solved by E. A. Walker and A. L. S. Corner. See [4].

Proposition 5.3. A torsion group $T=D \oplus R$, where $D$ is divisible and $R$ is reduced, is isomorphic to the maximal torsion subgroup of a second category group.

Proof. Clearly $T=D \oplus R$ is the torsion subgroup of $G=$ $D \oplus \operatorname{Ext}(Q / Z, R) . \quad G$ is of second category by Corollary 2.8.

Remark. Since $G / T \cong \operatorname{Ext}(Q / Z, R) / R \cong \operatorname{Ext}(Q, R)$ is divisible, $T$ is also dense in $G$.

6. Acknowledgements. I wish to express my gratitude to Professor J. M. Irwin who suggested this area of study and to the referee for suggesting Theorem 2.7 and for the present brief proof of Theorem 3.1.

\section{REFERENCES}

1. L. Fuchs, Abelian Groups, New York, Pergamon Press, (1960), 367p.

2. D.K. Harrison, Infinite Abelian groups and homological methods, Ann. Math. 69, (1959), 366-391.

3. J.M. Irwin, High subgroups of Abelian torsion groups. Pacific J. Math. 11, (1961), 1375-1384.

4. Irwin-Walker Editors, Topics in Abelian Groups, Chicago, Scott, Foresman and Co., (1963), 368p.

5. I. Kaplansky, Infinite Abebian Groups, Ann. Arbor, University of Michigan Press, (1954), 91p.

6. J.L. Kelly, General Topology, New York, D. Van Nostrand Co., Inc., (1955), 298p. 7. B.J. Pettis, A note on everywhere dense subgroups, Proc. Amer. Math. Soc. 3, (1952), 322-326.

New Mexico State University

IDAHO STATE UNIVERSITY 



\section{PACIFIC JOURNAL OF MATHEMATICS}

\section{EDITORS}

\section{H. SAMELSON}

Stanford University

Stanford, California

\section{R. M. BLUMenthaL \\ University of Washington \\ Seattle, Washington 98105}

*J. DugundjI

University of Southern California Los Angeles, California 90007

\section{RICHARD ARENS}

University of California

Los Angeles, California 90024

\section{ASSOCIATE EDITORS}
E. F. BECKENBACH
B. H. NeUManN
F. WOLF
K. YosIDA

\section{SUPPORTING INSTITUTIONS}

\author{
UNIVERSITY OF BRITISH COLUMBIA \\ CALIFORNIA INSTITUTE OF TECHNOLOGY \\ UNIVERSITY OF CALIFORNIA \\ MONTANA STATE UNIVERSITY \\ UNIVERSITY OF NEVADA \\ NEW MEXICO STATE UNIVERSITY \\ OREGON STATE UNIVERSITY \\ UNIVERSITY OF OREGON \\ OSAKA UNIVERSITY \\ UNIVERSITY OF SOUTHERN CALIFORNIA
}

\author{
STANFORD UNIVERSITY \\ UNIVERSITY OF TOKYO \\ UNIVERSITY OF UTAH \\ WASHINGTON STATE UNIVERSITY \\ UNIVERSITY OF WASHINGTON \\ AMERICAN MATHEMATICAL SOCIETY \\ CHEVRON RESEARCH CORPORATION \\ TRW SYSTEMS \\ NAVAL ORDNANCE TEST STATION
}

Mathematical papers intended for publication in the Pacific Journal of Mathematics should be typewritten (double spaced). The first paragraph or two must be capable of being used separately as a synopsis of the entire paper. It should not contain references to the bibliography. Manuscripts may be sent to any one of the four editors. All other communications to the editors should be addressed to the managing editor, Richard Arens at the University of California, Los Angeles, California 90024.

50 reprints per author of each article are furnished free of charge; additional copies may be obtained at cost in multiples of 50 .

The Pacific Journal of Mathematics is published monthly. Effective with Volume 16 the price per volume (3 numbers) is $\$ 8.00$; single issues, $\$ 3.00$. Special price for current issues to individual faculty members of supporting institutions and to individual members of the American Mathematical Society: $\$ 4.00$ per volume; single issues $\$ 1.50$. Back numbers are available.

Subscriptions, orders for back numbers, and changes of address should be sent to Pacific Journal of Mathematics, 103 Highland Boulevard, Berkeley 8, California.

Printed at Kokusai Bunken Insatsusha (International Academic Printing Co., Ltd.), No. 6, 2-chome, Fujimi-cho, Chiyoda-ku, Tokyo, Japan.

PUBLISHED BY PACIFIC JOURNAL OF MATHEMATICS, A NON-PROFIT CORPORATION

The Supporting Institutions listed above contribute to the cost of publication of this Journal, but they are not owners or publishers and have no responsibility for its content or policies.

* Paul A. White, Acting Editor until J. Dugundji returns. 


\section{Pacific Journal of Mathematics}

\section{Vol. 16, No. 2 December, 1966}

Loren N. Argabright, Invariant means on topological semigroups ........ 193

William Arveson, A theorem on the action of abelian unitary groups ...... 205

John Spurgeon Bradley, Adjoint quasi-differential operators of Euler

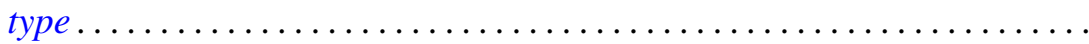

Don Deckard and Lincoln Kearney Durst, Unique factorization in power series rings and semigroups ........................... 239

Allen Devinatz, The deficiency index of ordinary self-adjoint differential operators..................................... 243

Robert E. Edwards, Operators commuting with translations ............ 259

Avner Friedman, Differentiability of solutions of ordinary differential equations in Hilbert space .............................. 267

Boris Garfinkel and Gregory Thomas McAllister, Jr., Singularities in a variational problem with an inequality ......................

Seymour Ginsburg and Edwin Spanier, Semigroups, Presburger formulas,

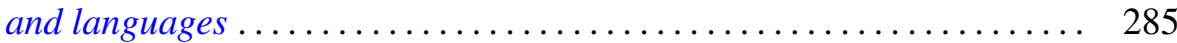

Burrell Washington Helton, Integral equations and product integrals . . . . . . 297

Edgar J. Howard, First and second category Abelian groups with the n-adic topology.........................................

Arthur H. Kruse and Paul William Liebnitz, Jr., An application of a family homotopy extension theorem to ANR spaces.

Albert Marden, I. Richards and Burton Rodin, On the regions bounded by homotopic curves

Willard Miller, Jr., A branching law for the symplectic groups ...

Marc Aristide Rieffel, A characterization of the group algebras of the finite

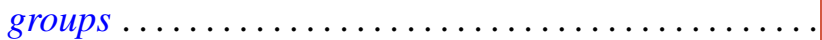

P. P. Saworotnow, On two-sided $H^{*}$-algebras

John Griggs Thompson, Factorizations of p-solvable groups ...

Shih-hsiung Tung, Harnack's inequalities on the classical Cartan

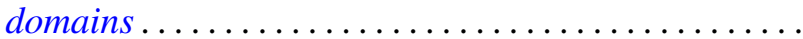

